\title{
Is a Self-Catering Holiday with the Family Really a Holiday for Mothers? Examining the Balance of Household Responsibilities While on Holiday from a Female Perspective
}

\author{
Ziene Mottiar \\ Technological University Dublin, ziene.mottiar@tudublin.ie \\ Deirdre Quinn \\ Technological University Dublin, deirdre.quinn@tudublin.ie
}

Follow this and additional works at: https://arrow.tudublin.ie/tfschhmtart

Part of the Arts and Humanities Commons, and the Social and Behavioral Sciences Commons

\section{Recommended Citation}

Mottiar, Z. \& Quinn, D. (2012) Is a self-catering holiday with the family really a holiday for mothers? Examining the balance of household responsibilities while on holiday from a female perspective, Hospitality \& Society, Vol. 2, No. 2. doi: 10.1386/hosp.2.2.197_1

This Article is brought to you for free and open access by the School of Tourism \& Hospitality Management at ARROW@TU Dublin. It has been accepted for inclusion in Articles by an authorized administrator of ARROW@TU Dublin. For more information, please contact arrow.admin@tudublin.ie, aisling.coyne@tudublin.ie, gerard.connolly@tudublin.ie.

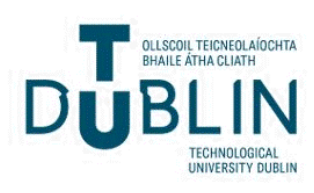




\section{Is a self-catering holiday with} the family really a holiday for mothers? Examining the balance of household responsibilities while on holiday from a female perspective

\section{ABSTRACT}

1.
The commonly cited definition of what constitutes a holiday is that it is a change from the norm, or an escape from everyday life. But is this the case if tourists are going on a self-catering holiday where many of the tasks from everyday life such as cleaning, minding children and cooking must still be undertaken? This research is specifically interested in the role of mothers, from their own perspective, on such holidays. It explores how household responsibilities are divided between partners when on holiday and questions does this differ from the situation when at home? In so doing this article adds to our understanding about the holiday experience from a

\section{KEYWORDS}

gender mother household responsibilities self-catering holidays household chores women 
gendered perspective. This study has found that actual experience while on holiday does differ according to gender. It is clear that while self-catering holidays are an 'escape' from the everyday, women and mothers' genderized roles are often maintained. A mixed-method approach involving two surveys and focus groups was employed. The field work for the study was undertaken in the Greater Dublin Area.

\section{INTRODUCTION}

In a broad hospitality sense gender has long been an issue of sociological interest. It is the nature of maleness and femaleness, and it concerns the psychological, social and cultural differences between male and female (Giddens 2009). Society has established roles and responsibilities for men and for women and mothers and fathers in the home, the workplace, and in terms of leisure and hospitality experiences. These roles have an impact on individual and family choices regarding holidays and their experiences of tourism and hospitality and thus from an industry and academic perspective greater understanding in this area is important.

Self-catering holidays are a popular way for families with children to access holidays. They are relatively less expensive and allow families greater freedom than perhaps hotel accommodation. A recent survey by MyHome.ie in Ireland reported a third of respondents saying cost was their primary reason for booking self-catering; this was followed closely by the facilities provided by a self-catering property and the opportunity to create 'a home from home' (Irish Times 2012). Accurate figures on the Irish market for self-catering properties (including private holiday homes and commercial properties) are difficult to gauge; this situation is not peculiar to the Irish market (Lynch and Johns 2007). However, in terms of providing some insight into the scale of the market, Fáilte Ireland (2010) report 369 self-catering properties comprising caravan and camping establishments, hostels and group self-catering schemes, and D. Quinn (2010) provides a guesstimate of 55,000-60,000 domestic holiday homes. This type of accommodation choice is of particular interest for this study as it necessitates a number of household chores to be undertaken by those on the holiday; many of the routine activities, such as cooking and cleaning, that are undertaken at home also need to be undertaken while on holiday.

The particular rationale for undertaking this study is the importance of understanding another aspect of how everyday life may, or may not, be mirrored in the tourist hospitality experience. The specific interest of this article lies in exploring, from the female perspective, the question of how men and women may, or may not, bring their home domestic responsibility roles of mothers and fathers to their self-catering holiday space, and the implications this has for the individual hospitality experience of their holiday.

The literature for this study starts with an examination of the broad sociological themes underlying this area of interest. In this first section gender is defined, and gender inequality is discussed with particular reference to household duties. The sociological literature around decision making within families is then commented upon. The second section of the literature review brings the aforementioned themes into a discussion of tourism. The literature relating to gender in tourism is reviewed, there is a focus on tourism decision making within the family, the gap in the literature regarding gender in tourism, and particularly regarding household tasks, is confirmed.

1. 2. 3. 4. 5. 6. 7. 8. 9. 10. 11. 12. 


\section{GENDER, GENDER ROLES AND THE FAMILY HOUSEHOLD}

Gender as a sociological construct is pervasive in the consideration of much of how we come to understand behaviour within society. Interestingly, sociology has mainly conducted research about men (Abbot et al. 2005); there are considerably fewer studies of women and topics, including mothering, that are particularly of relevance to them. This article aims to expand this literature. G. Murdoch (1949) argued that biological differences between men and women were the basis of the sexual division of labour. T. Parsons (1955) developed the theory of 'the expressive female', which views the role of woman in the family as that of nurturer, to provide warmth, security and emotional support. He contended that the male role is instrumental (i.e. the male is generally the breadwinner). In the 1960s, researchers were beginning to say differences between men and women are as much social as biological (Haralambos and Holborn 2008).

A. Oakley (1974) disagreed with both Parsons and Murdoch and considered 'the expressive female' to be a myth used to justify the suppression of women. She concludes that gender roles are culturally rather than biologically determined. In later work she declares 'the most important and enduring consequence of industrialization for women has been the emergence of the modern role of housewife as "the dominant mature feminine role" " (Oakley 1981: 10). It is the particulars of this role in the home, and that of a partner, and how they are, or are not, brought to the self-catering holiday experience, that is of interest in this study. Nowadays postmodernists say we should accept that 'humans today differ in the construction of their identities as men, women and children, husbands and wives, mothers and fathers [...] we should abandon the idea that one single narrative or story can help us to fulfil our potential' (Bilton et al. 2002: 253). This provides some interesting context from which to consider the roles and duties assumed by men and women in the case of a self-catering holiday.

Gender inequality has become a central concern for sociologists and it is generally thought to flourish because of the aforementioned socialization into different roles (Giddens 2009). There does appear to be a trend towards greater equality. In 1977, 65 per cent of all adults surveyed agreed with the comment 'It is much better for everyone involved if the man is the achiever outside the home and the woman takes care of the home and family'. By 2006, this was down to 36 per cent (NORC 2007: 321). Younger couples are more likely to have observed a loosening of gender stereotypes in their parental homes and are more likely to implement equality in their own homes (Warde and Hetherington 1993); there is some change in what we regard as a 'father tasks' and 'mother tasks'.

However, there is something of a 'lagged adaptation' in terms of the renegotiation of domestic tasks between men and women developing more slowly than women's entry into the labour market (Gershuny 1994). A Norwegian study (Kitterød and Pettersen 2006) found that there was selectivity in the chores men chose to take on when their female partners were not available. The study suggests that dual-earner parents rely mostly on external childcare to substitute for the mother's absence. The tasks selectively chosen by men tend to be shopping and cooking (van Berkel and de Graaf 1999). More recent economic conditions have however created a situation where there is more pressure on male workers, the process of equalization between male and female has stalled and there has been some reversion to old attitudes (Crompton et al. 2005). 
In terms of decision making within families and between men and women, changes have taken place over the last twenty years that may have altered the decision-making process in families (Kang and Hsu 2005). The main factors considered are a shift from the command to the negotiation method for family decision making (Clulow 1993); the presence of two incomes, which has increased status and options for women; and men doing more household chores and taking more domestic responsibilities (Hupfer 2002). All of these factors have led to more joint decision making.

\section{TOURISM, GENDER AND FAMILY HOLIDAYS}

In spite of the fact that 'gender is a core interest for sociology' (Crow and Pope 2008), this is an area which has received relatively little attention in the tourism literature, notable exceptions would be the contributions of Cara C. Aitchison (2009, 2007), Fiona Jordan and Cara C. Aitchison (2008), Fiona Jordan (2006), C. Cockburn-Wootten et al. (2008), Annette Pritchard et al. (2007b), Nigel Morgan (2000), Annette Pritchard et al. (2007a, 2007b) and Annette Pritchard (2000). Yet, the research that has been conducted shows that gender is relevant and plays a role in terms of issues such as marketing, holiday decision making, destination choice, entrepreneurship, employment and tourist behaviour. While a common topic of discussion in sociology is the division of household tasks, this has not been addressed in the tourism literature and the key question of this research is: do these roles and responsibilities differ when families are on holidays? When on a self-catering holiday, do mothers and fathers take on different tasks to those in the primary home? How are the personal dynamics and relationships within a family different when they are on holiday? So does the tourism experience fundamentally change the defined gender roles that individuals may have in their everyday life?

Aitchison (1998) notes that while feminist leisure studies has become established, an area of tourism and hospitality research which could be defined as feminist tourism studies does not exist in the same way. A search for literature on gender and hospitality, and gendered hospitality, provides a significant literature on gender as it relates to hospitality workplace practices but almost nothing from the perspective of the tourist or hospitality recipient. One interesting paper exploring the 'Expectations of the service experience offered by restaurants and cafés in Hamilton, New Zealand' (Mohsin et al. 2005) does suggest difference in actual experience according to gender. Another more recent paper concludes that expectations of hotel hospitality are influenced by personal factors such as gender (Ariffin and Maghzi 2012).

When analysing tourist behaviour, D. Collins and C. Tisdell conclude that 'gender has an important influence on travel demand' (2002: 142) and E. Frew and R. Shaw (1999) show that personality type and gender influences tourists' behaviour in terms of visiting attractions. N. McGhee et al. (1996) and V. J. Freysinger (1995) show that tourism motivations differ according to gender and F. Meng and M. Uysal state that 'gender differences were revealed in the perceived importance placed on destination attributes' (2008: 462). E. Kim et al. (2011) found distinct differences between gender groups regarding their motivations for using sources such as online hotel reviews.

Much of the previous attention to gender and tourism relates to what V. Kinnaird and D. Hall (1994) describe as the role of gender in tourism processes in terms of the economy, the environment and society. However, in a broader sense, one of the key contexts in which the issue of power, inequality
1.

2.

3.

4.

5.

6.

7.

8.

9.

10.

11.

12.

13.

14.

15.

16.

17.

18.

19.

20.

21.

22.

23.

24.

25.

26.

27.

28.

29.

30.

31.

32.

33.

34.

35.

36.

37.

38.

39.

40.

41.

42.

43.

44.

45.

46.

47.

48.

49.

50.

51.

52. 
1. and gendered relationships is most evident, and much researched, is within

2. the family and the home. From a tourism perspective, this dynamic of family 3. roles and relationships has focused on decision making as regards the holiday (e.g. Cosenza and Davis 1981; Madrigal 1995). Z. Mottiar and D. Quinn describe women as the 'gatekeepers to the tourism product as they initiate the idea of going on a holiday and collect the information. This shows a degree of power by women in households which can be exerted in the holiday decision' (2004: 158).

Previous studies highlight the importance of deconstructing the family group and examining the individual experiences and roles of its members. Some authors have researched mothering and leisure and tourism, and this highlights how the mothering role continues throughout the holiday and influences holiday decisions. For example, P. Davidson discussed how women choose to go to places such as Disney World as 'that was the place they could develop a particular relationship with their children [...] offer a new experience to their children in a way which fitted with what they wanted to achieve as a mother' (1996: 98). Furthermore, the experience of the holiday was described by one mother in Davidson's research as 'relaxation, being with the family, doing things that you don't normally do, like walking along the beach and that gave me satisfaction, to see them enjoying that, to see them having a play in the sand or looking for shells' (1996: 97). This highlights the importance of nurturing relationships while on holidays for women and also shows that the mothering role continues to be an important aspect in preparing, defining and enjoying a family holiday.

While such research does move the area of concern into the home and family this article seeks to probe further by dealing specifically with the issue of domestic responsibilities, and how they may differ between mothers and fathers, while on holiday. Much research on gender in sociology focuses on the division of labour or roles and responsibilities within households. Even though on self-catering holidays, in particular, many domestic responsibilities still need to be conducted, this discussion is clearly absent from the tourism literature.

National and international data repeatedly shows that women dominate in terms of domestic duties. The UN reports that women spend at least twice as much time as men on housework (2010). Similarly C. Cooper (2009) comments on how in Australia women do about two-thirds of the housework and in the United Kingdom time use surveys show that women spend double the amount of daily time that men do on domestic work (http://www.statistics.gov.uk/cci/nugget.asp?id=7). N. Feuvre says that,

It is necessary to take a closer look at the nature of tasks carried out by the minority of men who take part in domestic work. Around $60 \%$ of European men participate from time to time in shopping, an activity which can be equated with leisure and which allows them to directly control the family purse strings, while scarcely $30 \%$ participate in any way in cleaning or cooking.

It is interesting to note that some have observed the distinct support of women in acceptance of this status quo. B. Beagan et al. observe 'an overwhelmingly common rationale offered by women was that it was simply easier to do the foodwork themselves' (2008: 668). S. Kawamura and S. Brown note that 
the 'more the wives believe they matter to their husbands, the more likely they are to report the division of housework is fair, regardless of the share of housework wives perform' (2010: 976). What has not been studied to date however is whether the imbalance in terms of domestic work persists while on holiday? In a different environment with different routines and expectations do women still undertake the significant share of domestic work and so are genderdized roles maintained? Cockburn-Wootten et al. (2008) demonstrated that grocery shopping positions women within traditional discourses of housewife and mother and so restricts their access to leisure time. This article explores whether something similar is happening in the self-catering holiday context.

Tourists are motivated by a variety of factors including weather, activities, relaxation and for social reasons but change and escape have been identified as key motivations. E. Wickens observes that 'the theme of escape is a major pre-occupation in theoretical discourses on why people leave their home environment for holiday in another country' (2002: 843). But for a woman who is responsible for most of the household chores and often the childcare, if they go on a self-catering holiday how are they escaping their everyday life? As Davidson observes there is a 'contradiction of a work-filled event being accepted as a holiday experience' (1996: 89). She challenges the perception that holidays are about rest, relaxation, escape and at times excitement and that they constitute part of a work leisure dichotomy for women; instead they are 'defined as much by relationship and contribution to self-identity as it is by reduced pressure and pleasure' (Davidson 1996: 102). Building on this research, this article further discusses the issue of a holiday as an escape and also investigates to what extent couples' roles and responsibilities as parents change when they are on holiday so that in fact each is escaping their everyday role.

\section{METHODOLOGY}

This research study was undertaken from a loosely feminist perspective. Cockburn-Wootten et al. (2008) highlight that there is no one feminist method, however, there are common traits to feminist methods including an advocacy 'world-view', a participant-centred focus and an empathetic stance (Collis and Hussey 2009). This research involved a number of different phases and took a mixed-method approach whereby findings from two different survey instruments and focus group findings were compared and used to gain understanding of the issues. There is more insight to be gained from the combination of both qualitative and quantitative research 'than either form by itself' (Creswell 2009: 203). In each successive round of research the researchers learnt more about the issues of interest. The general approach does then incorporate some of the tenets of grounded theory.

In the first instance, a self-completion questionnaire was distributed to eleven couples, one for each partner to complete. The couples were randomly recruited from among the work colleagues of the authors across several categories of employment within Dublin Institute of Technology and a 100 per cent response rate was achieved. This exploratory questionnaire asked questions about roles and responsibilities at home in everyday life and the situation when on holidays. This first phase confirmed a number of issues, first that there was no discernable difference between the response of both parties in terms of the division of responsibilities and second that there does

1. 2. 3. 4. 5. 6. 7. 8. 9. 10. 11. 12. 13. 14. 15. 16. 17. 18. 19. 20. 21. 22. 23. 24. 25. 26. 27. 28. 
1. appear to be a difference in terms of the ways that responsibilities are shared at home and on holiday.

The second phase involved a quantitative approach that used a questionnaire and acquired 145 responses from a total of 250 questionnaires; a 58 per cent response rate. Distribution of the questionnaires in Dublin was based, in an iterative process, on the personal and also, again, professional networks of the authors. These respondents were split 60:40 between women and men. This approach was used in order to develop a broad picture of the issues of concern through the use of a detailed questionnaire that contained primarily closed questions. Phases 1 and 2 of the study were completed during May to July 2010. The questions for the questionnaires were developed directly from the main objectives of the study and were amended as appropriate from Phase 1 to Phase 2 . The analysis of both sets of questionnaires was facilitated by the use of SPSS. Frequencies, cross-tabulations and results of appropriate tests of association between variables were produced.

On reflecting on the findings from these first two phases of the study the decision was made to delve further into the issues raised. The third phase then added depth to our analysis as we conducted two focus groups during March 2011 in one of the authors' homes in suburban Dublin with women who have children and who have had self-catering holidays in the past year to discuss these issues in more detail. It was decided at this stage to concentrate on the female and mothering perspectives of this issue simply because it was perceived that men, and perhaps children, would constitute separately rich phases of a longer term overall research project and that is why the focus groups were comprised of women only. This in no way negates the importance of studying this issue from a male perspective, as $\mathrm{H}$. Schänzel and K. Smith (2011) note: there is a distinct shortage of research into fathers on holiday. Furthermore, a limitation of this study is that it focuses on white, heterosexual couples and only their perspectives of gendered domestic roles.

The first group consisted of eight women aged between mid-30s and 50; all had children and all had been on a self-catering holiday in the last year. All of these women worked in the home full time. The second focus group consisted of six women in the same age bracket who had also had self-catering holidays in the previous year but these were women who all worked outside the home. The specific age group of the participants in the focus groups must be acknowledged as women of this age, all (bar one) have children under the age of 12 , and so they form a particular component of female self-catering tourists and their situation is not the same as those who do not have children, those who have older teenage children or who have adult children. However, due to the particular dependence of young children on their parents, selection of this group, where there are many domestic responsibilities that need to be undertaken while children are still young, make them a particularly interesting group on which to focus. The analysis approach to this data was thematic (Spiggle 1994); the transcripts of the focus groups were dissembled and reassembled into themes of common interest between the two groups. Both authors were involved in this process which required complete immersion in the material.

\section{FINDINGS AND ANALYSIS}

In-depth analysis of both the quantitative and qualitative data resulted in the identification of three key themes; division of responsibilities, escape, and routine and changing relationships. These are discussed in detail below. All 
names used are the real names of the focus group participants, as agreed by the participants.

\subsection{Division of responsibilities}

Reflecting the national data discussed above, the first finding is that, at home, women are primarily responsible for household chores. A total of 60 per cent of female respondents state that they do most of the household chores when at home, while only 17 per cent of men said that they have primary responsibility. A stereotypical gender divide is evident with men predominantly doing gardening and women engaged in the cleaning and food responsibilities. It is notable that there is a very low figure for minding the children and this reflects the fact that a high proportion of the sample work full-time, thus those that have children must use some form of childcare. In the focus groups, it was clear that, for most, while this clear division of labour does exist, there appeared little animosity about this fact. For those who worked in the home, opinions can be encapsulated in Lucy's comment 'I am a stay-at-home mum and Mark is at work so I think that is fair enough... that's the deal'. While in the focus groups some of the women who worked outside the home were surprised when they thought about how much they did, with Dervilla commenting 'I am depressed, I never realized I did so much'. All noted that things were different at the weekend, in part because much of the domestic work happened Monday to Friday and also because male partners are at home and in particular would play a larger role in terms of bringing children places and minding them.

So the first key question is, is there a change in household responsibilities when on a self-catering holiday? This type of holiday necessitates that many of the household tasks listed in Table 1 continue to occur while on holiday. So does the person who does them at home continue to do them on holiday? As Table 2 shows, both male and female respondents do less household duties when on holiday. In every housework category, less respondents report that they do this job on holiday than at home, so overall, there are less domestic

$\begin{array}{lccc} & & & 32 . \\ & \text { Female } & \text { Male } & 33 . \\ \text { Clean the house } & 63 & 9 & 35 . \\ \text { Cook the food } & 59 & 17 & 36 . \\ \text { Decide what is for dinner } & 59 & 11 & 38 . \\ \text { Make decisions re. grocery shop } & 70 & 7 & 39 . \\ \text { Do the grocery shop } & 58 & 15 & 40 . \\ \text { Manage the household budget } & 33 & 24 & 41 . \\ \text { Pays the bills } & 33 & 39 & 43 . \\ \text { Mind the children } & 14 & 7 & 44 . \\ \text { Cuts the grass } & 9 & 64 & 45 . \\ \text { Wash the clothes } & 46 & 9 & 46 . \\ \text { Iron the clothes } & 38 & 13 & 48 . \\ \text { Clean the bathroom } & 49 & 17 & 49 . \\ \text { Table 1: Proportion of female and male respondents who say they solely or mostly } & 51 . \\ \text { do the following at home. } & & 52 . \\ & & & \end{array}$


1.

2.

3.

4.

5.

6.

7.

8.

9.

10.

11.

12.

13.

14.

15.

16.

17.

18.

19.

20.

21.

36.

37.

38.

39.

40.

41.

42.

43.

44.

45.

46.

47.

48.

49.

50.

51.

52.

\begin{tabular}{lcc}
\hline & At home & On holiday \\
\hline Clean the house & 41 & 26 \\
Cook the food & 42 & 30 \\
Decide what is for dinner & 40 & 24 \\
Make decisions re. grocery shop & 41 & 19 \\
Do the grocery shop & 41 & 14 \\
Manage the household budget & 30 & 25 \\
Mind the children & 14 & 4 \\
Wash the clothes & 46 & 37 \\
Iron the clothes & 38 & 23 \\
Clean the bathroom & 49 & 33 \\
\hline
\end{tabular}

Table 2: Proportion of all respondents who undertake household duties at home and on holiday.

responsibilities being undertaken while on holiday. However it is clear that many tasks are still being performed -37 per cent of people still wash clothes and 30 per cent cook food. The key issue of interest here is how the work is distributed between partners.

Table 3 focuses on the female respondents and asks how are household responsibilities shared when on holidays? Three key findings are exhibited. First, some duties are not done at all by most people while on holiday. The clearest example of this is ironing, which $51 \%$ do not do while on holiday, and in $28 \%$ of cases, neither partner cooks food or cleans the bathroom while on holiday and in $29 \%$ of cases neither partner washes clothes. Participants in the focus group also noted that when on holidays there is less work attached to keeping the house running for example Irene remarked that:

Even talking about kids having to be dressed ... They get into their swimming togs first thing in the morning and they stay in them, it is

\begin{tabular}{lcccc} 
& Female & Male & Both & Neither \\
\hline Cleans the house & 37 & 1 & 36 & 25 \\
Cooks the food & 36 & 10 & 26 & 28 \\
Decide what is for dinner & 29 & 6 & 53 & 12 \\
Makes decisions re. grocery shop & 26 & 5 & 61 & 8 \\
Do the grocery shop & 16 & 8 & 66 & 11 \\
Manage the household budget & 19 & 23 & 57 & 1 \\
Mind the children & 7 & 2 & 64 & 28 \\
Wash the clothes & 53 & 4 & 13 & 29 \\
Iron the clothes & 36 & 4 & 10 & 51 \\
Clean the bathroom & 45 & 5 & 22 & 28 \\
\hline
\end{tabular}

Table 3: While on holiday how are the household responsibilities shared? (Proportion of female only respondents.) 
brilliant. Nobody has to be fed, there is this big bowl of fruit in the centre of the table and people take it as they want it. Eating and dressing are just so easy and the focus is let's get out.

Similarly Dervilla said 'when you are on holidays you are out of the house, you are not thinking, I have to get on a wash, when you are on holidays you bring enough clothes, it flows, there is a relaxation'. Sheelagh agrees saying 'you don't have this endless list of jobs'.

The second pattern is that more responsibilities are shared -80 per cent of respondents agreed with the statement 'on holidays I feel like we share the household chores'. This finding is consistent with S. Kang and C. Hsu's (2005) work on household decision making in general and corresponds more specifically to Davidson's findings that on holidays 'women "get away" from pressure ... as there is assistance with childcare and housework' (1996: 95). This was also reflected in the focus groups when Lucy said 'we split a lot ... but there would be no ironing of clothes for example', and Claire said 'some things don't get done ... cleaning the bathroom wouldn't be high on my agenda when on holiday ... some of the cooking would fall away ... and I think most of those jobs get shared'. Comparing Table 1 and Table 3 shows that deciding what is for dinner, making decisions about grocery shopping and minding the children become shared responsibilities between the mother and the father. In her research, Feuvre (2003) similarly notes that the role of those men who do participate in domestic work tends to be in terms of shopping and they classify this as a leisure activity rather than a domestic chore. There is some resonance here of Bilton et al.'s (2002) postmodern construction of gender identity. It certainly could be argued that the tasks of shopping, deciding what is for dinner and minding children are the more rewarding of the domestic responsibilities explored and this will be discussed in more detail below.

The third finding is that some jobs remain primarily in the female domain. As Table 3 shows, washing and ironing the clothes, cooking the food and cleaning the bathroom are tasks that are either not done on holiday, or if they are, continue to be undertaken by the women. When asked in the focus groups about whether gender roles are maintained when on holidays there was general agreement that this is the case. An interesting discussion about efficiency ensued when Clare said the reason for this was 'because you can't change what you do automatically for two weeks that would make life very inefficient'. Lucy added:

because when you go away on holidays you want it to be efficient because even if efficiency is getting up and going to the beach for five hours you still want to do that, you don't want to be stuck in the house until twelve o'clock, taking forever, you want to [get ready] in the ten minutes that you normally do it in and just be gone.

Ursula took the example of packing the bag to go out saying if her husband is there then

at least he can take [the children] off while you pack the bag ... what would normally take you ten minutes would take you five. Whereas if you were to tell him to pack the bag it would take hours, and half the stuff would not be there when you got there. 
1. These findings echo those of Beagan et al. (2008) and J. Small (2005) as previ-

2. ously discussed.

The quantitative and qualitative data point to the fact that while on holiday some domestic responsibilities are simply not engaged in and others are shared much more than they are at home. But this is not the case with all domestic responsibilities and the focus groups show that participants feel that they maintain their gender roles and responsibilities, and parental roles, while on holiday and in so doing, create efficiencies which allow them and their families to maximize the holiday experience. Thus the holiday environment is still one in which gender inequality in terms of domestic chores exists although the inequality is less extreme and it is notable that the women see this state of affairs as an efficient way to maximize the enjoyment of the family.

\subsection{Escape and routine}

While it has been shown that many domestic responsibilities are shared on holidays rather than done solely by women, nonetheless if women are still cleaning clothes, cooking and cleaning the house or apartment on holiday then to what extent is it an escape from the everyday? Small (2005) contends that women on holiday are primarily seeking freedom from their roles as unpaid carers. In the focus groups when the issue of what a holiday is 'an escape from' was explored, it is the escape from a routine which is the most important attribute - Alison says 'the change in routine is the biggest thing for me when on holidays', Clare notes 'you just want to shake off the routine', Catherine says 'no routine, no bedtime, no certain bedtime, no certain getting up time, no certain lunchtime even, or certain mealtimes'. Sheelagh remarks that on holidays you 'can take it more as it comes'.

It is interesting to note though that it is not that there is no routine, what actually happens is that a holiday routine emerges. This reflects the findings of N. White and P. White (2007). Fiona observes 'I do think I get into a certain routine. I find I will be thinking about the picnic lunch when I get up and the girls still wake up at a certain time and we do get into that certain routine'. Irene says that

we found we would go over to the lake and spend the whole afternoon there, and the kids would come back and they would be a bit cranky at four or half four and we have found ourselves getting into a routine of putting on a DVD and we would just sit and relax and maybe have an aperitif or whatever and slowly get dinner ready. But I don't think that routine is any harm, I think children really like routines. But they are not rigid routines.

Sheelagh talks about these holiday routines as 'unrestricted routines'.

Activities that are part of routines at home such as shopping become much more of an experience when on holiday. When asked if shopping was different when away in both groups there was an animated consensus Alison said 'completely, it is pleasurable'. Just wandering through the shops that are different you would tend to buy different things. Irene noted that when on holiday

the children enjoy shopping ... there are fish displays which you would take photographs of and the kids are fascinated with it. And they have 
loads of samples of fruit and you can try things, and they are buying melons and all sorts of things and it is so fresh and everything tastes different.

So the routine of shopping becomes a more pleasurable family activity that transforms it from being a domestic chore and routine into a family experience and adventure. There is then some agreement here with the work of Cockburn-Wootten et al. (2008), who examines routine and non-routine shopping behaviour from a gender perspective.

It is also interesting to observe how while it is great to escape an everyday routine those women in the focus group who holiday for longer periods enjoy and look forward to returning to the routine. Dervilla said:

Last summer I went away for five weeks and it was brilliant. But I was a little bit putting on a face because the reality of it was I was five weeks out of routine, the kids were out of routine they were up until eleven or twelve at night, they wouldn't have a sleep during the day like the locals so their behavior went south ... so I was well and truly ready to come back after five weeks.

So it is clear that being on holiday is an escape. Some domestic responsibilities do not have to be undertaken, others become shared responsibilities with partners and others, such as shopping, can become a much more positive experience which is shared by all in the family. While the escape from everyday routines is what makes a holiday, it is interesting to note that other routines emerge while on holiday, but these routines are different as they are less rigid and restricted. Thus it is not having a routine that a holiday facilitates escape from, it is the nature of the routine which changes while on holiday. In some ways it is this relaxed routine that is part of the positive memories of the holiday, the vibrant and excited discussion about the experience of food shopping while abroad and the discussion of what a typical day on holiday is shows that many like the fact that they have this relaxed routine that is part of the holiday experience. When they recollect about holidays, it is many of these factors which constitute the memories of the holiday.

\subsection{Roles and relationships within the family}

As holidays are an escape and there is a shift in domestic responsibilities among women, are relationships and roles different when on holiday? Interestingly the survey showed that in spite of the fact that more chores are shared, only 36 per cent of respondents 'feel like my role in the family is different'. This different role is reflected by Dervilla's comment that her role would change a bit from 'being an organizer and carer ... I would tend to sit back a bit and my husband would kind of take over'. But the belief that their mothering role did not change while on holidays was also the consensus view of the focus groups, with Alison saying 'I think your role as the mother doesn't change ... you are always wondering if they are ok'. Lucy adds 'whenever we go anywhere it is "how much food we have, do we have nappies, how much water do we have, are we going to be near toilets? All that kind of stuff that is my role"'. Viv commented that

I sometimes feel I am more wrecked after a holiday because there is so much more ... running around ... when on holiday with the family it's 
fun and you are having a great time but there is still a lot involved in shifting around a family.

For most, it seems that parental roles do not change on holidays; this is in part because minding children and a family continues even while on holiday. It also may indicate that respondents do not define their role within the family in terms of domestic chores but more in terms of parenting which continues while on holiday. Davidson (1996: 98) discusses the importance of relationships for women and how the holiday functions as a place where women can indulge in any of these roles, such as the role of mother, in a more satisfying way'.

In terms of relationships, 45 per cent of the survey respondents feel that 'on holidays my relationship with my partner is quite different than it is when we are at home'. In the focus groups, there was much discussion around the fact that you have more time with your partner and more relaxed time; Yvonne says 'it is 24/7 with your partner when you are on holidays', there was general agreement that you discuss things as a couple more when you are away 'because you have time to do it' (Ursula). According to Sheelagh, there is time for a 'real chat... it is not squeezed in between don't forget this and don't forget that, at home you talk a lot about the "business of the day" . Two participants whose husbands work away during the week spoke about the adjustment that is needed when on holiday as they are spending all day every day together and Claire B said that while 'we would look forward to [holidays] I have to admit, when he goes back to work, I am happy and he is happy to go back to work as well. Because it is stressful'.

Relationships with children are described as 'far more relaxed' and 'there are less conflicts'. The lack of television and technology was also noted by a number of participants as a positive thing about holidays. The being relaxed with children and doing things like swimming together, playing and having bicycle races were cited as things that mothers are much more likely to do on holiday than at home. It was also noted that when a child asked you to do something with them on holiday you would do it straight away, whereas at home you would say just wait until I get this job done first .... and then at the end of the day you would realize you had never done that with them (Dervilla). Davidson discusses how 'a holiday functions as a place where women can indulge in any of [their] roles, such as the role of mother, in a more satisfying way' (1996: 98) and this is a theme that emerged from the focus groups. The importance of the role of the father in terms of children also needs to be noted and this reflects the work of Schänzel and Smith who identify a key role of fathers on holidays as the 'main entertainer of the children' (2010: 18).

\section{CONCLUSION}

What this article illustrates is that first when we analyse the experience of holidays we need to be cognizant of the fact that this experience can be very different for men and women, mothers and fathers. The literature to date shows that gender has an influence in terms of tourism demand and motivations, but this study shows that the actual experience while on holiday can also be different. There are clear product development and marketing implications of such a finding for the hospitality and tourism sectors. Second, although holidays are an 'escape' from the everyday, in terms of a self-catering holiday for women and mothers, genderdized roles are most often maintained. They still 
do many of the same domestic tasks as they would when they are at home, with the only difference being that some responsibilities rather than being done alone are shared. Some jobs such as shopping and childcare are shared and some other tasks such as ironing often are not done while on holiday. Nonetheless, where cleaning clothes and preparing food still need to be done, it is predominantly the women who still perform these tasks, thus maintaining a higher proportion of domestic responsibility even while on holiday; they maintain their genderdized roles.

So an escape for many female tourists does not necessarily involve an escape from everything at home, but from a pragmatic point of view, it means less domestic responsibility, and by them maintaining their genderdized role they can maximize the holiday experience by efficiently carrying out the tasks that they do at home in the quickest time possible. It is also notable that a family routine emerges on holiday and often this incorporates domestic responsibilities, but the routines are much less rigid and restricted than those in their everyday life.

This research has shown that the imbalance in the division of household labour continues while on holiday. This reflects the fact that national data shows that even in situations where both partners work outside the home, women take on more of the domestic responsibilities. On a positive note, there is more sharing of some responsibilities while on holiday - although the relative 'niceness' of such responsibilities has been discussed above. What is interesting to note is that the focus group discussions did not indicate dissatisfaction with this situation; it made sense to the women for them to do what they do at home as they could do it most efficiently and so maximize the time spent doing the things that the family wanted. This reflects the Beagan et al. (2008) finding that women felt it was 'simply easier' to do the jobs themselves. In her study R. Deem showed that while 'housework was a major feature of many women's lives ... for some the "break" from the routine of paid work was more significant than the continuity of domestic obligations' (1996). This perhaps goes some way to explaining the lack of dis-satisfaction.

From the hospitality industry perspective, it is also important to note that the women prioritize the satisfaction of the family group as a whole and take the actions necessary to maximize the group's enjoyment as a whole. When the mothers, who participated in the focus group discussed their holidays, it was in terms of their families. They were choosing a self-catering holiday as they said this is what suited the children best and they were continuing to be primarily responsible for getting children ready, cleaning and cooking as this meant that the family as a whole would have more time to enjoy the holiday. This reflects the work of Davidson (1996) discussed above, whereby holiday choices are made in the context of what is best for children. This shows that the holiday experience for women when holidaying with families is constrained by the needs of the group as a whole and the women appear to maintain their gender roles in order to ensure that the holidays goes as smoothly as possible for the family as a whole. While they enjoy the break away from everyday routines, the holiday itself creates a routine because 'your role as a mother never changes' (Alison). From a feminist perspective, the unequal division of labour in households and the genderdized roles of women as mothers are maintained while on holidays.

The contribution of these findings to the literature is important from a number of different perspectives. In the first instance, they add to the sociological debate about gender and household responsibilities. Second, they make a contribution to the debate about to what extent holidays are an escape

1. 2. 3. 4. 5. 6. 7. 8. 9. 10. 11. 12. 13. 14. 15. 16.

17. 18. 19. 20. 21. 22. 23. 24. 25. 26. 27. 28. 29. 30. 31. 32. 33. 34. 35. 36. 37. 38. 39. 40. 41. 42. 43. 44. 45. 46. 47. 48. 49. 50. 51. 52. 
1.

from the everyday, and third, in terms of the research on gender, tourism and hospitality, it provides another avenue of research which is concerned with the family and the division of labour while on holiday. It is clear that while women do classify a self-catering holiday as a holiday and an escape, in reality, the gender inequality that is evident generally within the home is perpetuated while on holiday. There is evidently plenty of scope for further research, most immediately among fathers, in this area that links hospitality, gender and tourism. This area is firmly rooted in what has been characterized as the current sociological debate in hospitality and tourism (Lashley et al. 2007).

\section{REFERENCES}

Abbot, P., Wallace, C. and Tyler, M. (2005), An Introduction to Sociology: Feminist Perspectives, 3rd ed., Abingdon: Routledge.

Aitchison, C. C. (1998), 'Gendered space: The contribution of feminist geography to discourses of gender and leisure', paper presented at Leisure in a Globalised Society: Inclusion or Exclusion, World Leisure and Recreation Association 5th World Congress, Sao Paulo, Brazil, October.

- (2007), 'Gender, sport and identity: Introducing discourses of masculinities, femininities and sexualities', in C. C. Aitchison (ed.), Gender, Sport and Identity: Masculinities, Feminities and Sexualities, Abingdon: Routledge, pp. $1-4$.

- (2009), 'Gender and tourism discourses: Advancing the gender project in tourism studies', in T. Jamal and M. Robinson (eds), Handbook of Tourism Studies, London: Sage, pp. 627-40.

Ariffin, A. and Maghzi, A. (2012), 'A preliminary study on customer expectations of hotel hospitality: Influences of personal and hotel factors', International Journal of Hospitality Management, 31: 1, pp. 191-98.

Beagan, B., Chapman, G., D'Sylva, A. and Bassett, B. (2008), '“It's just easier for me to do it": Rationalizing the family division of foodwork', Sociology, 42: 4, pp. 653-71.

Bilton, T., Bonnett, K. and Jones, P. (2002), Introductory Sociology, 4th ed., Basingstoke: Palgrave Macmillan.

Clulow, C. (1993), New families? Changes in societies and family relationships', Sexual and Marital Therapy, 8: 3, pp. 269-73.

Cockburn-Wootten, C., Pritchard, A., Morgan, N. and Jones, E. (2008), “'It's her shopping list!" exploring gender, leisure, and power in grocery shopping', Loisir/Leisure, 32: 2, pp. 407-36.

Collins, D. and Tisdell, C. (2002), 'Gender and differences in travel life cycles', Journal of Travel Research, 41: 2, pp. 133-43.

Collis, J. and Hussey, R. (2009), Business Research, 3rd ed., Basingstoke: Palgrave Macmillan.

Cooper, C. (2009), 'Women still do majority of housework', ABC, http://www. abc.net.au/news/stories/2009/03/25/2525756.htm. Accessed 12 April 2011.

Cosenza, R. M. and Davis, D. L. (1981), 'Family vacation decision making over the family life cycle: A decision and influence structure analysis', Journal of Travel Research, 20: Winter, pp. 17-23.

Creswell, J. (2009), Research Design; Qualitative, Quantitative and Mixed Methods Approaches, 3rd ed., Thousand Oaks: Sage.

Crompton, R., Brockmann, M. and Lyonette, C. (2005), 'Attitudes, women's employment and the domestic division of labour: A cross-national analysis in two waves', Work, Employment and Society, 19: 2, pp. 213-34. 
Crow, G. and Pope, C. (2008), 'Editorial forward: Sociology and gender', 1. Sociology, 42: 3, pp. 397-99.

Davidson, P. (1996), 'The holiday and work experiences of women with young children', Leisure Studies, 15: 2, pp. 89-103.

Deem, R. (1996), 'Women, the city and holidays', Leisure Studies, 15: 2, pp. 105-19.

Fáilte Ireland (2010), Tourism Employment Survey 2010, Dublin: Fáilte Ireland.

Feuvre, N. (2003), 'Women and employment', in P. Ballarin, C. Euler, N. Le Feuvre and E. Raevaara (eds), Women in the European Union, University of Helsinki Research, http://www.helsinki.fi/science/xantippa/wee/weetext/ wee224.html\#2.4.2.\%20Men's\%20participation \%20in \%20domestic\%20 labour. Accessed 10 June 2011.

Frew, E. and Shaw, R. (1999), 'The relationship between personality, gender, and tourism behavior', Tourism Management, 20: 2, pp. 193-202.

Freysinger, V. J. (1995), 'The dialectics of leisure and development for women and men in mid-life: An interpretative study', Journal of Leisure Research, 27: 1, pp. 61-70.

Gershuny, J. (1994), 'The domestic labour revolution: A process of lagged adaptation', in M. Anderson, F. Bechofer and J. Gershuny (eds), The Social and Political Economy of the Household, Oxford: Oxford University Press.

Giddens, A. (2009), Sociology, 6th ed., Cambridge: Polity Press.

Haralambos, M. and Holborn, M. (2008), Sociology, 7th ed., London: Collins.

Hupfer, M. (2002), 'Communicating with the agentic and the command man: Are stereotypic advertising appeals still relevant?', Academy of Marketing Science Review, 3: 1, pp. 1-15.

Irish Times (2012), 'Staying put is the new going abroad', Irish Times Property Section, 7 June, p. 2.

Jordan, F. (2006), 'Life's a beach and then we diet: Discourses of tourism and the "beach body" in UK women's lifestyle magazines', in A. Pritchard, N. Morgan and I. Ateljevic (eds), Tourism, Gender and Embodiment: Critical Issues of Gender, Sexuality and the Body, Wallingford: CABI.

Jordan, F. and Aitchison, C. C. (2008), 'The sexualisation of the tourist gaze: Solo female tourists' experiences of gendered power, surveillance and embodiment', Leisure Studies, 27: 4, pp. 329-49.

Kang, S. and Hsu, C. (2005), 'Dyadic consensus on family vacation destination selection', Tourism Management, 26: 4, pp. 571-82.

Kawamura, S, and Brown, S. (2010), 'Mattering and wives' perceived fairness of the division of household labor', Social Science Research, 39: 6, pp. 976-86.

Kim, E., Mattila, A. and Baloglu, S. (2011), 'Effects of gender and expertise on consumers' motivation to read online hotel reviews', Cornell Hospitality Quarterly, 52: 4, pp. 399-406.

Kinnaird, V. and Hall, D. (1994), Tourism a Gender Analysis, Chichester: Wiley.

Kitterød, R. and Pettersen, S. (2006), 'Making up for mothers' employed working hours: Housework and childcare among Norwegian fathers', Work, Employment and Society, 20: 3, pp. 473-92.

Lashley, C., Lynch, P. and Morrison, A. (eds) (2007), Hospitality; a Social Lens, Oxford: Elsevier.

Lynch, P. and Johns, N. (2007), 'The self-catering accommodation market: A review of electronic and other sources', International Journal of Hospitality Management, 26:2, pp. 293-309.

2.

3.

4.

5.

6.

7.

8.

9.

10.

11.

12.

13.

14.

15.

16.

17.

18.

19.

20.

21.

22.

23.

24.

25.

26.

27.

28.

29.

30.

31.

32.

33.

34.

35.

36.

37.

38.

39.

40.

41.

42.

43.

44.

45.

46.

47.

48.

49.

50.

51.

52. 
Madrigal, R. (1995), 'Personal values, traveler personality type and leisure travel style', Journal of Leisure Research, 27:2, pp. 125-42.

McGhee, N., Loker-Murphy, L. and Uysal, M. (1996), 'The Australian international pleasure travel market: Motivations from a gendered perspective', The Journal of Tourism Studies, 7: 1, pp. 45-57.

Meng, F. and Uysal, M. (2008), 'Effects of gender differences on perceptions of destination attributes, motivations, and travel values: An examination of a nature-based resort destination', Journal of Sustainable Tourism, 16: 4, pp. 445-66.

Mohsin, A., McIntosh, A. and Cave, J. (2005), 'Expectations of the service experience offered by restaurants and cafés in Hamilton, New Zealand', Journal of Hospitality and Tourism Management, 12: 2, pp. 108-16.

Mottiar, Z. and Quinn, D. (2004), 'Couple dynamics in household tourism decision making: Women as the gatekeepers?', Journal of Vacation Marketing, 10: 2, pp. 149-61.

Murdoch, G. (1949), Social Structure, New York: Macmillan.

NORC (2007), General Social Surveys, 1972-2006: Cumulative Codebook, Chicago: National Research Centre.

Oakley, A. (1974), The Sociology of Housework, Oxford: Martin Robinson.

- (1981), Subject Women, Oxford, Martin Robinson

Parsons, T. (1955), 'The American family: Its relations to personality and social structure', in T. Parsons and R. Bales (eds), Family Socialization and Interaction Process, New York: Free Press, pp. 3-34.

Pritchard, A., El-Sherif Ibrahim, N. and Jones, E. (2007a), '(Un)veiling women's employment in the Egyptian travel business', in A. Pritchard, N. Morgan, I. Ateljevic and C. Harris (eds), Tourismand Gender: Embodiment, Sensuality and Experience, Wallingford: CABI, pp. 290-301.

Pritchard, A., Morgan, N., Atlejevic, I. and Harris, C. (2007b), Tourism and Gender: Embodiment, Sensuality and Experience, Wallingford: CABI.

Quinn, D. (2010), 'Holiday home, sweet home; a phenomenological approach to second home living in Ireland', unpublished Ph.D. thesis, University of Wales, Cardiff.

Schänzel, H. (2012), The inclusion of fathers, children and the family group into tourism research on families', in H. Schänzel, I. Yeoman and E. Backer (eds), Family Tourism Multidisciplinary Perspectives, Bristol: Channel View Publications, pp. 67-80,

Schänzel, H. and Smith, K. (2010), 'Where's dad? Challenging the limits of true gender scholarship in family tourism research', in S. Crispin, A. Dunn, S. Fishwick, A. Franklin, D. Hanson, D. Reiser, R. Shipway, M. Wells and C. Baxter (eds), Proceedings of the 20th Annual Conference Council for Australian University Tourism and Hospitality Education (CAUTHE), Hobart, Tasmania: School of Management, University of Tasmania, February, pp. 8-11. (2011), 'The absence of fatherhood: Achieving true gender scholarship in family tourism research', Annals of Leisure Research, 14: 2-3, pp. 129-40.

Small, J. (2005), 'Women's holidays: Disruption of the motherhood myth', Tourism Review International, 9: 2, pp. 139-54.

Spiggle, S. (1994), 'Analysis and interpretation of qualitative data in consumer research', Journal of Consumer Research, 21: 3, pp. 491-503.

UN (2010), 'The world's women 2010 trends and statistics', United Nations Statistical Division, http://unstats.un.org/unsd/demographic/products/ Worldswomen/wwwork2010.htm. Accessed 22 November 2010. 
van Berkel, M. and de Graaf, N. (1999), 'By virtue of pleasantness? Housework and the effects of education revisited', Sociology, 33: 4, pp. 785-808.

Warde, A. and Hetherington, K. (1993), 'A changing domestic division of labour? Issues of measurement and interpretation', Work, Employment and Society, 7: 1, pp. 23-46.

Wickens, E. (2002), 'The sacred and the profane: A tourist typology', Annals of Tourism Research, 29: 3, pp. 834-51.

White, N. and White, P. (2007), 'Home and away: Tourists in a connected world', Annals of Tourism Research, 34: 1, pp. 89-104.

\section{SUGGESTED CITATION}

Mottiar, Z. and Quinn, D. (2012), 'Is a self-catering holiday with the family really a holiday for mothers? Examining the balance of household responsibilities while on holiday from a female perspective', Hospitality \& Society 2: 2, pp. 197-214, doi: 10.1386/hosp.2.2.197_1

\section{CONTRIBUTOR DETAILS}

Ziene Mottiar is a lecturer in Tourism at the College of Arts and Tourism at Dublin Institute of Technology, Ireland. Ziene has a range of research interests and publications, in particular in the areas of tourism entrepreneurship, tourism firms, destinations, regional development and gender.

Contact: School of Hospitality Management and Tourism, Dublin Institute of Technology, Cathal Brugha St, Dublin 1, Ireland.

E-mail: ziene.mottiar@dit.ie

Deirdre Quinn, Ph.D., is a lecturer in Tourism at the College of Arts and Tourism at the Dublin Institute of Technology. She teaches modules in Consumer Behaviour and Marketing and has a particular expertise in research methods. Her research areas of interest include everyday and tourist life, second home living, gender and innovative qualitative methodologies.

Contact: School of Hospitality Management and Tourism, Dublin Institute of Technology, Cathal Brugha St, Dublin 1, Ireland.

E-mail: deirdre.quin@dit.ie

Ziene Mottiar and Deirdre Quinn has asserted their right under the Copyright, 